\title{
Near infrared spectroscopy as a rapid and inexpensive means of dietary analysis for a marine herbivore, dugong Dugong dugon
}

\author{
Jessica André, Ivan R. Lawler* \\ School of Tropical Environment Studies and Geography, James Cook University, Townsville, Queensland 4811, Australia
}

\begin{abstract}
The objective of this study was to evaluate the potential of near infrared reflectance spectroscopy (NIRS) to estimate the botanical composition of seagrass mixtures in the stomach contents of dugongs more rapidly and cost-effectively than by conventional means. NIRS estimation of dietary composition is achieved by developing calibration equations that relate NIR spectra of samples to laboratoryderived values for botanical composition. Once calibration equations have been developed, these characteristics can be estimated for further samples from their spectra alone. We developed calibration equations using samples from the stomachs of 26 dugongs (from a total data set of 128 dugongs) and validated them against a further set of 14 stomach samples. Nine dietary components were identified, 5 of which made up less than $5 \%$ of the total diet. Acceptable calibrations were obtained for the major components of dugong diets: seagrass rhizomes (pooled across all species) and the leaves of the seagrasses Thalassia hemprichii, Syringodium isoetifolium and Cymodocea species. We did not attain satisfactory calibrations for minor $(<10 \%)$ dietary components. NIRS is a valid method for obtaining rapid information on the main components of the dugong diet. With larger calibration sets and fresh samples it should also be able to provide information on minor dietary components. NIRS is applicable to dietary studies of marine herbivores and should thus be of value to marine ecologists generally.
\end{abstract}

KEY WORDS: Near-infrared spectroscopy · Dietary analysis · Herbivory · Dugong · Seagrass

\section{INTRODUCTION}

Dugongs are large marine herbivores that feed almost solely on seagrasses (Marsh et al. 1982). Their ecology is thus intimately tied to their use of the available seagrass resources and this had led to several studies of their diets, based largely on sorting samples of the stomach contents into the different botanical species based on their appearance under a microscope (Heinsohn \& Birch 1972, Marsh et al. 1982, Erftemeijer et al. 1993). These techniques are laborious and timeconsuming, taking up to $1.5 \mathrm{~d}$ per sample. When large numbers of stomach contents have to be analysed, the time and cost of conventional methods may become limiting and thereby prohibit the complete analysis of these data sets and thus, faster alternative techniques would be invaluable. Near infrared reflectance spec- troscopy (NIRS) is one such method, as it allows the holistic investigation of the composition of organic samples in a rapid, cost-effective and repeatable manner (Shenk \& Westerhaus 1993, 1994). As outlined below, once calibration equations are developed, sample composition can be estimated using the Near Infrared (NIR) spectra alone, reducing analysis time by an order of magnitude or more.

For 3 decades now, NIRS has been used in the field of agriculture, with the evaluation of forage quality for domesticated animals being the main focus (Givens et al. 1997). In recent years, however, its utility has come to be recognised by ecologists (Foley et al. 1998). NIRS has been found to be an effective means for measuring the botanical composition of different plant communities, determining plant nutrients and secondary metabolites, analysing minerals and soils and even 
measuring such poorly defined aspects of organic composition as plants' resistance to insects (Windham et al. 1988, Morra et al. 1991, Rutherford \& Van Staden 1996, Foley et al. 1998). Aragones (1996) has shown that NIRS can be used to examine the chemical composition (e.g. nitrogen, fibre) of seagrasses. In this paper we investigate the applicability of NIRS to determining the species composition of samples taken from the stomachs of dugongs. NIRS offers a faster alternative to the Weibel graticule used in previous studies, where the objective has been to examine the major contributors to the diet, and when the time constraints of laboratory analysis become restrictive.

The basic principles behind NIRS can be summarised as follows (more detailed coverage is provided by Givens et al. 1997 and Foley et al. 1998). When a sample of organic material is irradiated with NIR light, it is absorbed at frequencies corresponding to characteristic vibrations of the chemical bonds within particular functional groups (Foley et al. 1998). All other frequencies are either reflected or transmitted (Givens et al. 1997). NIR radiation is mainly absorbed by $\mathrm{C}-\mathrm{H}$, $\mathrm{N}-\mathrm{H}$ and O-H bonds (Foley et al. 1998), which are the main components of plant and animal tissues. Because the chemical constituents of a tissue determine the type and number of bonds present (and therefore the wavelengths and amount of light absorbed), the analysis of the reflected spectra of a sample provides information on the chemical composition of that sample (Foley et al. 1998).

Direct interpretation of the spectral absorbances can, however, be difficult, as the peaks in the NIR region consist of overtones and combinations of bands from primary absorption in the mid-infrared (Givens et al. 1997). Analysis of organic composition of samples via NIR analysis must thus be done indirectly. Estimates of the chemical composition of mixtures of unknown composition can be made by comparing spectra of those samples with the spectra of similar samples whose composition has been measured via conventional laboratory analysis (Foley et al. 1998). Calibration equations are derived, usually using multivariate regression-style analyses that relate the spectra to the laboratory values. These equations can then be used to estimate the composition of unknown samples, provided that they are part of the same spectral population (Foley et al. 1998).

Several studies have investigated the possibility of using NIRS to estimate the proportions of individual species in plant mixtures, and they have evaluated the accuracy of the technique with promising results (Petersen et al. 1987, Coleman et al. 1990, GarciàCriado et al. 1991, Pitman et al. 1991, Wachendorf et al. 1999). Analyses of livestock oesophageal samples via NIRS, which one may expect to be more difficult because of partial digestion, have also produced acceptable results (Hill et al. 1988, Volesky \& Coleman 1996). We therefore considered it likely that the technique would also allow characterisation of the diet of marine herbivores from samples of stomach contents.

This study was conducted as part of a larger study examining the diet of dugongs in Torres Strait, between Australia and Papua New Guinea. Stomach samples were collected as part of a study into the indigenous fishery for dugongs in the region (Kwan 2002). It was determined when the study commenced that time constraints would not allow the entire sample set to be examined by conventional techniques. We show below that adopting NIRS allowed us to meet the objectives of the larger study, which were to compare the diets of dugongs and green turtles in the Torres Strait and to examine differential resource use (André et al. unpubl. data), with time to spare.

\section{MATERIALS AND METHODS}

A total of 128 samples of dugong stomach contents were available for this study. All samples came from dugongs caught by local hunters on Mabuiag Island, Torres Strait (Kwan 2002). The stomach contents were collected from the anterior part of the stomachs (where food is least digested), preserved in a formalin-based solution (5\% formalin/95\% seawater) and stored away from direct light for several months.

Collection of reflectance spectra. A sub-sample (approximately $40 \mathrm{~g}$ ) of the stomach contents of each dugong was dried in an oven at $50^{\circ} \mathrm{C}$ for $72 \mathrm{~h}$. Samples were then ground using a Cyclotec 1093 Sample Mill (Tecator). Before collecting the spectra for NIRS, samples were kept in an oven at $40^{\circ} \mathrm{C}$ for $1 \mathrm{~h}$ to remove any moisture absorbed during storage, and placed into a desiccator to cool to room temperature (water has a broad absorbance band that may obscure other relationships in the reflectance spectrum of the sample). Prior to scanning, each sample was placed into a sample cup; care was taken to ensure that each sample was spread evenly and packed to a consistent degree of compression (Foley et al. 1998). Sample cups were then placed in a NIR Systems 6500 spectrometer (equipped with a spinning cup module, Foss NIRSystems) to obtain their reflectance spectra. In order to minimise instrument variation in the measurement of spectra, the NIRS instrument was housed in a room maintained at constant temperature and humidity.

Calibration. Calibration and predictions were conducted using the WinISI II-Version 1.02A software (Infrasoft International).

Selection of calibration set: After scanning the entire sample set, a subset was chosen for calibration. A sta- 
tistical approach was taken to enable the minimum number of samples to be selected to encompass the spectral variation of the population of samples, thus minimising the cost and effort expended in laboratory analyses.

The dimensions of the spectral data were first reduced to principal component scores, then the distances between them in multivariate space (Mahalanobis distance) were calculated (Shenk \& Westerhaus 1993, 1994). The distances between each sample and the average spectrum for the population, expressed as the 'global $\mathrm{H}^{\prime}$ (=Mahalanobis distance values standardised by dividing by the average for the population) were then calculated. This procedure establishes spectral boundaries for the population and allows the detection of samples with extreme spectra (i.e. those with global $\mathrm{H}>3$ ) that would have an excessive influence on the calibration (Shenk \& Westerhaus 1993, 1994). Two outliers were eliminated from the dataset via this process.

Samples to be included in the calibration set were then selected using the neighbourhood $\mathrm{H}$ concept, where the neighbourhood for any 1 sample is the multivariate 'space' close to that sample. One sample is selected per neighbourhood, as it is considered that the others are sufficiently close in chemical composition that the single sample can represent them in a calibration. We used a neighbourhood H-value of 1.625 which selected 26 samples for calibration (approximately $18 \%$ of the total data set). The $\mathrm{H}$-value we selected was slightly higher than is common practice because of the very strong time constraint under which this study was conducted. Smaller values would restrict each neighbourhood such that there would be more neighbourhoods, and thus more samples selected in the calibration set. We could only afford to analyse 40 samples (including an independent validation setsee below) out of the 128 to develop the calibration in order for the study to be viable and completed on schedule. Other studies have used between 20 (Volesky \& Coleman 1996) and $40 \%$ (Garcià-Criado et al. 1991) of the total data set for calibration, but the absolute size of our calibration set is smaller. We describe below precautions taken, such as cross validation of the calibration equations and validation with an independent data set (Anonymous 1995), such that we are confident of the use of this calibration set for the purpose described.

Laboratory reference values for calibration: The samples selected for calibration were analysed with the Weibel graticule technique as described in detail by Channells \& Morrissey (1981). In summary, 8 slides were prepared from each sample of stomach contents by evenly spreading a sub-sample of digesta over each slide. Ten sites per slide were then scanned quantita- tively to determine the contribution of the various dietary components to the volume of the sample. This was achieved by counting the number of graticule line endpoints that each dietary component intercepts. Results were expressed in percentage of volume.

Seagrasses were identified under a microscope on the basis of cellular structure, using the seagrass collection from the School of Tropical Environment Studies and Geography, James Cook University, Townsville, Queensland, published photographs (Lanyon 1986) and reference slides created from seagrass specimens collected by Cairns Department of Primary Industry and Michelle Waycott (James Cook University). Because of the fragment size and the state of digestion of some samples, seagrass could not always be identified to the species level. Cymodocea serrulata and C. rotundata were not always distinguishable and were pooled simply as 'Cymodocea'. Similarly, Halophila ovalis and $H$. spinulosa were pooled under Halophila, as the 2 species had very similar cell structure and could not always be differentiated. Seagrass rhizomes could not be systematically identified to species and were pooled across all species for cohesion. Note therefore, that hereafter references to amounts of material other than rhizomes necessarily refer only to the aboveground part of the plant, and may be underestimates, as they do not take into account the contribution of rhizomatous parts of that species.

The accuracy of the microhistology analyses was assessed by having the same person perform blind duplicates of several samples. The standard error of the laboratory (SEL) was calculated according to the formula: SEL $=\sqrt{ }\left(\sum\left[y_{1}-y_{2}\right]^{2} / \mathrm{N}\right)$, where $y_{1}$ and $y_{2}$ are duplicates of a sample and $\mathrm{N}=$ total number of samples (Smith \& Flinn 1991).

Development of the calibration equation: We used modified partial least squares regression to develop the calibration, as recommended by Shenk \& Westerhaus $(1993,1994)$. We used the full range of wavelengths recorded, being every $8 \mathrm{~nm}$ between 408 and $2492 \mathrm{~nm}$. A variety of mathematical treatments that remove irregularities in the data, such as the effect of particle size, were tested (variations of 1 st, 2 nd or 3rd order derivatives of the spectra and different sizes of smoothing intervals - Table 1), and the best equation was selected on the basis of estimates of the standard error of calibration (SEC $=$ error due to differences between estimates of species composition made using microscopy and NIRS-predicted values within the calibration set), the standard error of prediction (SEP = error due to differences between microscopic analysis values and NIRS-predicted values outside the calibration set) and the standard error of cross validation $(\mathrm{SECV}=$ error due to differences between microscopic analysis values and NIRS-predicted values within the 
Table 1. Calibration statistics, including the regression method (MPLS-SC and MPLS-N = modified partial least square-scatter correction and = no scatter correction, respectively), number of samples (N), standard error of calibration (SEC), cross validation $(\mathrm{SECV})$, and laboratory (SEL), coefficient of determination of the regression equation between laboratory references and near infrared reflectance spectroscopy (NIRS)-predicted values $\left(\mathrm{r}^{2}\right)$, number of principal components (Terms) and mathematical treatment (Maths: numbers refer respectively to the order of the derivative of the spectrum and the size of gap, 1st and 2nd smooth intervals used—see Shenk \& Westerhaus 1993 for details)

\begin{tabular}{|c|c|c|c|c|c|c|c|c|}
\hline Genus (method) & $\mathrm{N}$ & Range (\%) & $\operatorname{SEC}(\%)$ & $\operatorname{SECV}(\%)$ & SEL $(\%)$ & $r^{2}$ & Terms & Maths \\
\hline Rhizome (MPLS-SC) & 26 & $12-67$ & 4.11 & 5.17 & 5.83 & 0.99 & 6 & $2,4,4,1$ \\
\hline Thalassia (MPLS-SC) & 26 & $0-81$ & 1.93 & 10.68 & 3.62 & 0.99 & 6 & $2,4,4,1$ \\
\hline Cymodocea (MPLS-SC) & 26 & $2-34$ & 1.93 & 7.35 & 2.35 & 0.98 & 6 & $2,4,4,1$ \\
\hline Syringodium (MPLS-SC) & 25 & $0-61$ & 5.52 & 5.09 & 3.78 & 0.86 & 6 & $2,4,4,1$ \\
\hline Halophila (MPLS-SC) & 25 & $0-9.5$ & 0.86 & 2.26 & 0.82 & 0.94 & 6 & $2,4,4,1$ \\
\hline Halodule (MPLS-N) & 26 & $0-1.7$ & 0.13 & 0.50 & 0.70 & 0.97 & 5 & $3,4,4,1$ \\
\hline Enhalus (MPLS-N) & 7 & $0-0.3$ & 0.03 & 0.05 & 1.62 & 0.58 & 6 & $2,4,4,1$ \\
\hline Thalassodendron (MPLS-N) & 11 & $0-6.8$ & 0.10 & 0.11 & 2.55 & 0.10 & 5 & $3,4,4,1$ \\
\hline Algae (MPLS-SC) & 17 & $0-4$ & 0.25 & 0.18 & 0.50 & 0.24 & 5 & $3,4,4,1$ \\
\hline
\end{tabular}

cross-validation sets). These terms measure the accuracy of the relationship between the NIR spectral absorbances and the laboratory reference values in the regression equations. The coefficient of determination $\left(\mathrm{r}^{2}\right)$, slope and intercept of the regression equations, as well as the bias (difference between the mean actual value and the mean predicted values for a component) are also important factors in model selection. For brevity we present here only the final model for each dietary component.

Modified partial least squares regression requires cross validation to guard against overfitting (i.e. adding too many wavelengths to the model; Anonymous 1995). The calibration set was arbitrarily divided into a number of small groups. Estimation was made of the values for each group based on the calibration developed from the remaining samples. In turn, predictions were made for all groups with the average of prediction for all groups becoming the final calibration equation (Shenk \& Westerhaus 1993, 1994).

We also used an independent data set to validate the calibrations. That is, we tested the estimates produced by applying the calibration to a set of 14 samples that were not part of the calibration set, but for which we derived laboratory reference values.

\section{RESULTS}

\section{Laboratory reference analyses}

Nine seagrasses, Thalassia hemprichii, Syringodium isoetifolium, Cymodocea serrulata, C. rotundata, Enhalus acoroides, Thalassodendron ciliatum, Halophila ovalis, H. spinulosa, and Halodule uninervis, were identified microhistologically from the 40 samples (calibration + validation set) of stomach contents of dugongs. As noted previously, C. serrulata and $C$. rotundata were pooled as 'Cymodocea', $H$. ovalis and $H$. spinulosa were pooled under Halophila and seagrass rhizomes were pooled across all species. (All species are referred to as genera alone hereafter.)

Algae were also found in the samples but most of them could not be identified due to the small size of the fragments. The total concentration of algae never exceeded $4 \%$. Overall, rhizome and Thalassia were the most important components in the diet, constituting 39.30 and $33.83 \%$ of the stomach contents, respectively. Syringodium and Cymodocea accounted for 11.06 and $10.58 \%$ of the total diet, respectively. Enhalus, Halodule, Halophila and Thalassodendron

Table 2. Validation statistics, including the difference between the mean actual value and the mean predicted values for a component (Bias), standard error of prediction (SEP) and slope (SE slope). See Table 1 for definitions

\begin{tabular}{|c|c|c|c|c|c|c|c|}
\hline Genus (method) & $\mathrm{N}$ & Range (\%) & Bias & $\operatorname{SEP}(\%)$ & Slope & SE slope & $\mathrm{r}^{2}$ \\
\hline Rhizome (MPLS-SC) & 14 & $8.8-53$ & -2.32 & 9.21 & 1.00 & 0.07 & 0.94 \\
\hline Thalassia (MPLS-SC) & 14 & $6-85$ & 6.27 & 13.87 & 0.90 & 0.07 & 0.93 \\
\hline Cymodocea (MPLS-SC) & 14 & $1.3-14$ & -1.99 & 4.64 & 1.27 & 0.16 & 0.82 \\
\hline Syringodium (MPLS-SC) & 12 & $0-28$ & -3.13 & 6.66 & 1.08 & 0.12 & 0.86 \\
\hline Halophila (MPLS-SC) & 14 & $0.5-9$ & 0.82 & 2.76 & 0.67 & 0.18 & 0.50 \\
\hline Halodule (MPLS-N) & 11 & $0-4.2$ & 0.36 & 0.58 & 0.10 & 0.12 & 0.06 \\
\hline
\end{tabular}


had a low frequency of occurrence and accounted for approximately $5 \%$ of the total diet.

Overall, the precision of the microscopic analyses (SEL) was acceptable (Table 1), the highest value being for rhizomes (SEL $=5.83 \%$ ).

\section{Calibration}

Good calibrations were obtained initially for rhizome, Thalassia, Cymodocea, Halodule, Halophila and Syringodium (Table 1). No acceptable predictions were produced for Enhalus, Thalassodendron or algae, as indicated by the poor $\mathrm{r}^{2}$ values $(<0.70)$ for the relationship between the values estimated by NIRS and those derived from microhistological analyses. The SEC values for the estimated components were small, ranging from 0.86 to $5.52 \%$. SEC and SECV values were close for most components except Thalassia and Cymodocea.

\section{Validation}

Validation was performed for the 6 dietary components that resulted in acceptable predictions in the calibration stage. The validation statistics indicated an excellent fit for (Table 2) rhizome, Thalassia, Syringodium and Cymodocea. Predictions for Halophila and Halodule, however, were not acceptable, with $\mathrm{r}^{2}<70 \%$ (Table 2). Plots of laboratory-determined versus estimated proportions of Thalassia, rhizome, Cymodocea and Syringodium showed linear relationships for these 4 dietary components (Fig. 1). The
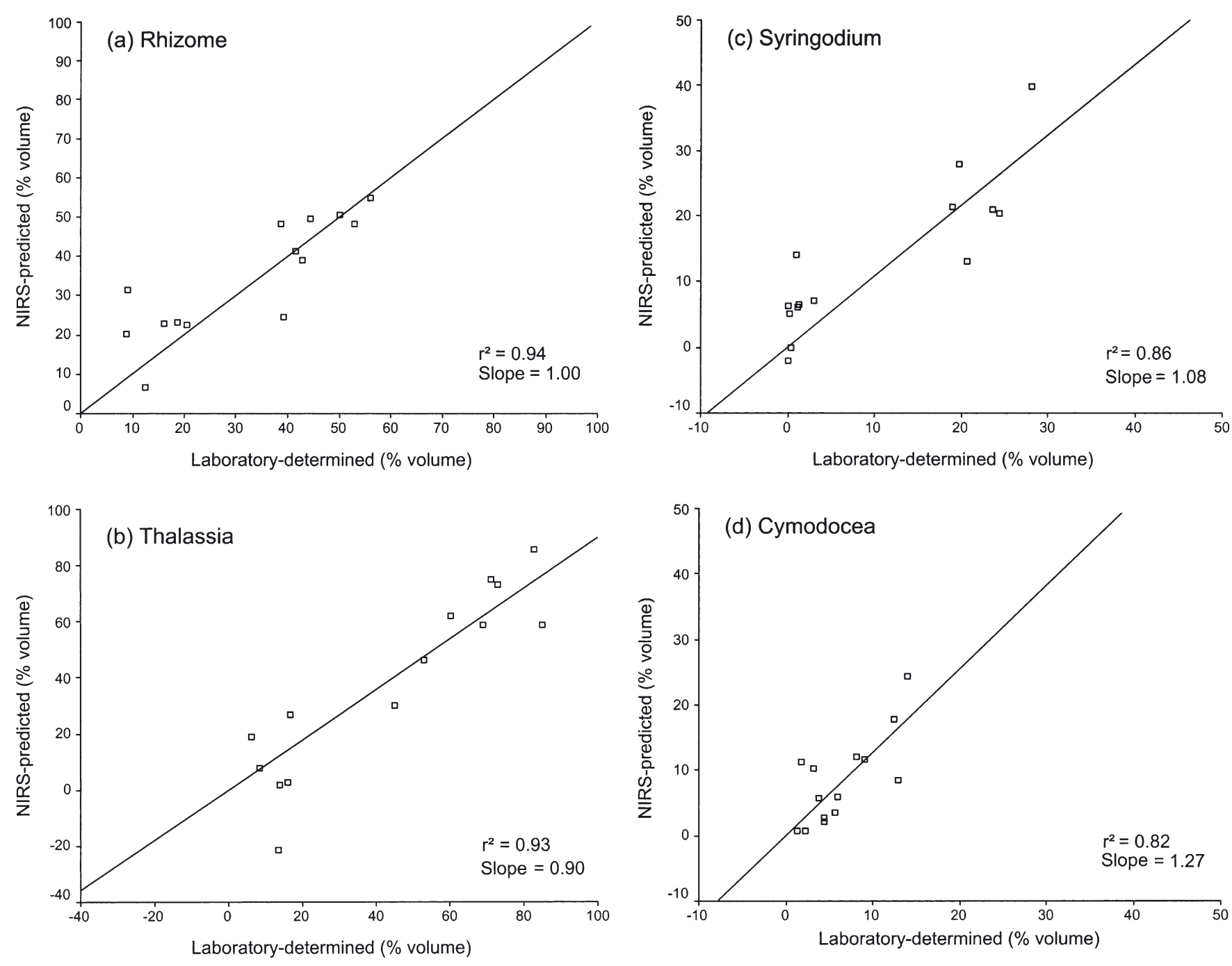

Fig. 1. Relationship of near infrared reflectance spectroscopy (NIRS)-predicted percentages of (a) rhizome, (b) Thalassia, (c) Syringodium, and (d) Cymodocea to laboratory-determined percentages for the validation set 
slopes were not significantly different from 1.00 (Table 2), indicating that the calibrations were accurate. Bias was acceptable, with a maximum of 6.27 for Thalassia (Table 2).

\section{DISCUSSION}

Of the 9 dietary components found in the stomachs of dugongs from Torres Strait, 4 were estimated accurately by NIRS. These were the major dietary components, and thus NIRS is a valid means to examine most of the variability in the diet of these dugongs. There were several factors that may have been expected to impede the development of acceptable calibrations for minor dietary components: (1) a relatively small calibration set; (2) the samples were partially digested; (3) the samples were stored in formalin; and (4) some groups were pooled because they were not morphologically distinct under conventional analysis. The utility of the NIRS technique for studies of other systems should be viewed in light of these factors, as we discuss in more detail below.

Rhizome, Thalassia, Syringodium and Cymodocea were the 4 constituents accurately predicted by NIRS. These 4 seagrass components totalled $95 \%$ of the diet. Bias was acceptable, with values ranging from -3.1 (Syringodium) to $6.3 \%$ (Thalassia). Bias never exceeded SEP, and was therefore of little consequence since random error exceeds systematic error (Coleman et al. 1990). The regression coefficients for the relationship between the laboratory-derived versus the NIRS-estimated values for the independent validation set for these dietary components were high, with a minimum $\mathrm{r}^{2}$ of 0.82 for Cymodocea. This suggests that these 4 dietary items were chemically distinct and present in sufficient quantities for NIRS to predict them accurately. The fact that differences in the chemical composition of tropical seagrasses between plant parts (i.e. leaves vs rhizomes) and species (e.g. Syringodium vs Cymodocea) have been reported by Aragones (1996) supports this hypothesis.

It is interesting that quantities of rhizomes could be estimated well, despite the pooling of rhizomes across species. The most likely explanation for this is that there is some chemical feature, or features, common to rhizomes that are distinct from those found in leaf tissues. To be able to develop a strong mechanistic explanation for this requires a detailed knowledge of the underlying chemistry. This would include an examination of the important wavelengths in the calibration equations, relating them to independent information on the chemistry of each source of material (e.g. McIlwee et al. 2001). At this point there is not sufficient information to do that in this case, but it does not pre- clude the application of the method. Provided sufficient care is taken in calibration, and ensuring that samples to be predicted come from the same spectral population, then an understanding of the underlying mechanism, while desirable, is not essential (Foley et al. 1998, McIlwee et al. 2001).

The 5 dietary components that were not predicted accurately all had a small range of values, with maximum values of ca. $10 \%$ (Tables $1 \& 2$ ). This suggests that $10 \%$ may be a limit under which NIRS cannot pick up the chemical signature of a species or that the lab work is not repeatable when occurrence is small (but see below). An earlier study by Volesky \& Coleman (1996) found similar results. They estimated the botanical composition of oesophageal extrusa samples from livestock and concluded that only major botanical components ( $>10 \%$ of the diet) were predicted with acceptable precision and accuracy. The fact that minor dietary components could not be predicted accurately was, however, of little concern in this study, as these components made up less than $5 \%$ of the total diet and were therefore not significant to the objectives of the broader study.

Acceptable predictions were obtained for Halodule and Halophila in the initial calibration, and we were optimistic that we would be able to estimate these via NIRS. However, the equation failed to produce adequate predictions for the independent validation set. SEP and bias were small but $\mathrm{r}^{2}$ values for both species were unacceptably low (Table 2). The low value of the regression coefficient for Halodule may be explained by the greater range of values in the validation set relative to the calibration set. Halodule was present only in low concentrations in the calibration set (0 to $1.7 \%$ ) while in the validation set, values ranged between 0 and $4.2 \%$. Thus, attempts to make estimations on some samples in the validation set resulted in extrapolation beyond the range of the calibration equation and likely led to the poor agreement between laboratory-derived and NIRS-estimated values. The reason for the weak agreement between the calibration and the validation sets for Halophila is not known. We suspect that it derives from low resolution in the laboratory method. As noted earlier, it was difficult to distinguish between $H$. ovalis and $H$. spinulosa, and these were pooled in the analysis. These 2 species, however, appear to be substantially chemically distinct (Aragones 1996) and differences in the ratios of the 2 between samples in the calibration set and those in the validation set may have led to poor agreement, as observed.

Enhalus, Thalassodendron and algae had acceptable SEC and SECV values, but the $\mathrm{r}^{2}$ values for the relationship between the laboratory and NIRS estimated values were low $\left(\mathrm{r}^{2}=0.58,0.24\right.$ and 0.13 respectively). This is probably due to the small amounts of these constituents in the calibration set. Enhalus ranged only 
from 0 to $0.3 \%$ in the calibration set, whereas Thalassodendron and algae ranged from 0 to $6.8 \%$ and 0 to $4 \%$, respectively. Moreover, few samples in the calibration set contained these components, thus the calibration set was effectively considerably smaller for these items (Table 1).

Our data set, and hence calibration set, is relatively small due to the nature of the animal on which we work. We were fortunate to have the unusually large number of 128 samples from dugong stomachs, as these samples were available from a 2 yr study of hunting of dugongs by Torres Strait Islanders (Kwan 2002). We suspect studies of other marine herbivores may have much larger numbers of replicates (e.g. Keshava et al. 1988, Forbes 1996). The primary appeal of adopting NIRS methodology in laboratory analysis is to save the time and cost of conventional methods. Benefits are only gained if the work expended in developing the calibrations exceeds that saved in reducing the laboratory work. We determined that examination of the technique's applicability to our study must be based on a total of approximately 40 samples, considering a specific and firm time constraint. As with all statistical techniques, the precision of the NIRS calibrations improves with increasing numbers of samples. Most authors use ca. 50 samples or more for calibration (Hill et al. 1988, Garcià-Criado et al. 1991, Anonymous 1995, Volesky \& Coleman 1996). That we are able to describe dugong diets very well with a smaller calibration set indicates that the technique may provide even finer resolution as the sample set grows. This may circumvent some of the problems described above. One of the advantages of NIRS is that once a calibration has been developed, it can be used, and added to, by subsequent studies (Shenk \& Westerhaus 1993, 1994), as we intend to do with this data set.

Much of the discussion above has addressed the perceived accuracy of the NIRS estimation as determined by comparison with the laboratory-derived values. In fact, the major source of error is often the reference analyses themselves. Inaccuracies in the laboratory analysis result in poor calibrations. The study by Volesky \& Coleman (1996) provides the most appropriate illustration of this problem. In their assessment of the applicability of NIRS to resolving the botanical composition of mixtures of terrestrial grasses, they manually created a set of mixed samples that they could then use to determine the accuracy of each method. In fact, they found that laboratory analyses were the largest source of error and that it was this that led to poor calibrations, rather than problems with the NIRS technique itself. The calibration can only be as good as the values used to derive it (Shenk \& Westerhaus 1993, 1994).

In this study, the accuracy of the microhistological analysis, and hence quality of the data used for calibration, mostly depended on the level of digestion of the stomach contents. In very digested samples, microhistological identification became difficult because seagrass fragments lost their characteristic cellular structure and species were likely to be confused. For example, $C y$ modocea was likely to be confused with Thalassodendron in very digested samples, although the 2 species have very distinct cell structure in non-digested fragments. Duplicate analyses of some stomach contents revealed that variability was greater in very digested samples than in little digested samples, but the overall SEL (i.e. the accuracy of the microhistological analyses) was acceptable. Error in the laboratory analyses is thus a contributor to the imprecision in the NIRS analyses, but is unlikely to be the major source of error for the calibration. We cannot determine at this stage how much, if at all, the level of digestion or storage in formalin interferes with the chemical distinctness of each species, and thus the ability to estimate them by NIRS.

Another possible source of error may come from chemical variation in seagrass. Seagrass chemical composition is known to change with season (Preen 1995). In this study, stomach contents were collected over a 3 yr period, from September 1997 to September 1999. Sampling date could have introduced variation in the chemical properties and spectral absorption (Volesky \& Coleman 1996). Additional variation could come from dugongs feeding on various seagrass beds in Torres Strait, as site location and depth are also known to influence the chemical constitution of seagrass (Aragones 1996). These are issues that will be addressed in expanding the calibration set in subsequent studies.

It is instructive to clearly illustrate the savings to be made in adopting NIRS for dietary analysis. Determination of diet composition via the microhistological method takes ca. $1 \mathrm{~d}$ per sample. This assumes samples are simply taken from storage and spread unprepared on microscope slides for immediate analysis. Thus, for the 128 samples that we had, it would have taken over 6 mo (assuming a standard Monday to Friday 09:00 to $17: 00 \mathrm{~h}$ working week) to complete these analyses. Monetary costs are low for this example because no reagents are used and the work has been done as part of a postgraduate research program. However, both the cost of staff time and the reagent cost of chemical analyses that also can be done by NIRS (e.g. nitrogen content, fibre, carbohydrates) may be prohibitive (Shenk \& Westerhaus 1993, 1994). The NIRS analysis took a total of $14 \mathrm{wk}$. This included (1) laboratory analysis of calibration and validation sets $(45 \mathrm{~d})$; (2) drying and grinding of 128 samples (4 d); and (3) development of calibrations and application to remaining samples $(7 \mathrm{~d})$. Thus, even in this study with relatively small numbers of samples, we were able to save over 3 mo laboratory time while meeting the objectives of the study. 


\section{Conclusions}

This study shows that the main dietary items found in dugong stomachs can be identified and estimated via NIRS. This has the capacity to greatly increase the scope of dietary studies, while minimising expense and effort. The overall study, of which this paper is a part, has 128 samples. Thus, a relatively small calibration set was used to develop equations to make the investment in developing the technique cost effective. Even so, acceptable calibrations for the major dietary items were developed and have allowed the remainder of the samples to be estimated by NIRS alone. This has reduced laboratory work for this study by over $50 \%$. NIRS could not be used to adequately estimate dietary items constituting less than $10 \%$ of the diet, but this did not prevent us meeting the objectives of the larger project. That this level of resolution could be achieved with a small calibration set, and samples in various stages of digestion stored in formalin is an excellent illustration of the utility of the technique. NIRS is a technique that may have wide applicability and great value to studies of marine herbivore diets where conventional methods limit the ability to examine larger datasets.

\section{LITERATURE CITED}

Anonymous (1995) Standard practices for infrared multivariate quantitative analysis (designation E1655-00). American Society for Testing and Materials, West Conshohocken, PA

Aragones LV (1996) Dugongs and green turtles: grazers in the tropical seagrass system. PhD thesis, James Cook University of North Queensland, Townsville

Channells P, Morissey J (1981) Technique for analysis of seagrass genera preset in dugong stomachs, including a key to North Queensland seagrasses based on cell details. In: Marsh H (ed) The dugong. James Cook University of North Queensland, Townsville, p 176-179

Coleman SW, Christiansen S, Shenk JS (1990) Prediction of botanical composition using NIRS calibrations developed from botanically pure samples. Crop Sci 30:202-207

Erftemeijer PLA, Djunarlin, Moka W (1993) Stomach content analysis of a dugong (Dugong dugon) from South Sulawesi, Indonesia. Aust J Mar Freshw Res 44:229-233

Foley WJ, McIlwee AP, Lawler IR, Aragones L, Woolnough AP, Berding N (1998) Ecological applications of near infrared spectroscopy - a tool for rapid, cost-effective prediction of the composition of plant and animal tissues and aspects of animal performance. Oecologia 116:293-305

Forbes GA (1996) The diet and feeding ecology of the green sea turtle Chelonia mydas in an algal-based coral reef community. PhD thesis, James Cook University of North Queensland, Townsville

Garcià-Criado B, Garcià-Ciudad A, Perez-Corona ME (1991) Prediction of botanical composition in grassland herbage samples by near infrared reflectance spectroscopy. J Sci Food Agric 57:507-515

Givens DI, De Boever JL, Deaville ER (1997) The principles, practices and some future applications of near infrared spectroscopy for predicting the nutritive value of foods for animals and humans. Nutr Res Rep 10:83-114

Editorial responsibility: Kenneth Heck (Contributing Editor), Dauphin Island, Alabama, USA
Heinsohn GE, Birch WR (1972) Foods and feeding habits of the dugong, Dugong dugon (Erxleben), in Northern Queensland, Australia. Mammalia 36:412-422

Hill NS, Petersen JC, Stuedemann JA, Barton FE II (1988) Prediction of percentage leaf in stratified canopies of alfalfa with near infrared reflectance spectroscopy. Crop Sci 28:354-358

Keshava, Joseph PS, Joseph MM (1988) Feeding habits of the pearl-spot Etroplus suratensi (Bloch) in the NethravataGurpur estuary. In: Joseph MM (ed) Proc First Indian Fisheries Forum, 4-8 December 1987. Asian Fisheries Society, Mangalore, p 203-206

Kwan DK (2002) Towards a sustainable indigeous fishery for dugongs in Torres Strait: a contribution of empirical data and process. PhD thesis, James Cook University of North Queensland, Townsville

Lanyon JM (1986) Seagrasses of the Great Barrier Reef. Great Barrier Reef Marine Park Authority, Townsville

Marsh H, Channels PW, Heinsohn GE, Morrissey J (1982) Analysis of stomach contents of dugongs from Queensland. Aust Wildl Res 9:55-67

McIlwee AM, Lawler IR, Cork SJ, Foley WJ (2001) Coping with chemical complexity in mammal-plant interactions: near-infrared spectroscopy as a predictor of Eucalyptus foliar nutrients and of the feeding rates of folivorous marsupials. Oecologia 128:539-548

Morra MJ, Hall MH, Freeborn LL (1991) Carbon and nitrogen analysis of soil fractions using near-infrared reflectance spectroscopy. Soil Sci Soc Am J 55:288-291

Petersen JC, Barton FE II, Windham WR, Hoveland CS (1987) Botanical composition of tall fescue-white clover mixtures by near infrared reflectance spectroscopy. Crop Sci 27 : $1077-1080$

Pitman WD, Piacitelli CK, Aiken GE, Barton FE II (1991) Botanical composition of tropical grass-legume pastures estimated with near-infrared reflectance spectroscopy. Agron J 83:103-107

Preen A (1995) Diet of dugongs-are they omnivores? J Mamm 76:163-171

Rutherford RS, Van Staden J (1996) Towards a rapid nearinfrared technique for prediction of resistance to sugar borer Eldana saccharina Walker (Lepidoptera, Pyralidae) using stalk surface wax. J Chem Ecol 22:681-694

Shenk JS, Westerhaus MO (1993) Analysis of agriculture and food products by near infrared reflectance spectroscopy. Infrasoft International, Port Matilda, PA

Shenk JS, Westerhaus MO (1994) The application of near infrared spectroscopy (NIRS) to forage analysis. In: Fahey GCJ, Mosser LE, Mertens DR, Collins M (eds) National Conference on Forage Quality Evaluation and Utilization. American Society of Agronomy, Crop Science Society of America, and Soil Science Society of America, Madison, WI, p 406-449

Smith KF, Flinn PC (1991) Monitoring the performance of a broad-based calibration for measuring the nutritive value of two independent populations of pasture using near infrared reflectance (NIR) spectroscopy. Aust J Exp Agric 31:205-210

Volesky JD, Coleman SW (1996) Estimation of botanical composition of esophogeal extrusa samples using near infrared reflectance spectroscopy. J Range Manage 49:163-166

Wachendorf M, Ingwersen B, Taube F (1999) Prediction of the clover content of red clover- and white clover-grass mixtures by near infrared reflectance spectroscopy. Grass Forage Sci 54:87-90

Windham WR, Fales SL, Hoveland CS (1988) Analysis of tannin concentration in Sericea lespedeza by near infrared reflectance spectroscopy. Crop Sci 28:705-708

Submitted: September 3, 2002; Accepted: May 8, 2003

Proofs received from author(s): July 22, 2003 